\title{
Ergonomy of paraplegic patients working with a reciprocating gait orthosis
}

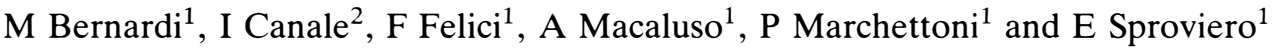 \\ ${ }^{1}$ Istituto di Fisiologia Umana, Facoltà di Medicina, Università di Roma 'La Sapienza', Piazzale Aldo Moro 5, \\ I-00185 Roma, Italy; ${ }^{2}$ IRCCS Clinica S Lucia, Roma, Italy
}

A reciprocating gait orthosis $(\mathrm{RGO})$ is, among others, the most widely adopted device to restore the standing and walking capability of paraplegic patients. The aim of the present study was the evaluation of the energy demand $\left(\dot{\mathrm{VO}}_{2}\right)$, and cardiopulmonary load (HR and $\dot{V E}$ ) imposed on the subject by different working tasks while sitting in a wheelchair or standing using a RGO. In addition, a comparison with the performance of normal subjects was also attempted. The RGO use allowed a dramatic improvement of patients" mobility and reach space in the workplace. A further advantage provided by the use of the RGO was represented by the increased mobility of the subjects with respect to the wheelchair confined situation. The energy demand and the cardiorespiratory load imposed on the subjects by the use of the RGO were not different from those observed both in the same subjects sitting in a wheelchair and in the controls. The energy demand slightly exceeded the values typical of light work and was, thus, compatible with the normal duration of a working day. On the other hand, the cardiac load corresponded to that typical of moderate activity, thus limiting the duration of the working task to 5-8 h. Based on the ergometry test, all of the working activities considered can be classified as aerobic activities, energy demand being under the ventilatory threshold.

Keywords: paraplegic subjects; reciprocating gait orthosis; working ability; rehabilitation

\section{Introduction}

The restoration of working ability is one of the major tasks in the rehabilitation of disabled people. An ergonomic workplace must be designed in accordance with the user's reach space, which implies that the work environment must be greatly rearranged in order to fit in with the needs of a wheelchair worker. ${ }^{1}$ Orthoses which permit paraplegic patients to stand and to walk have been greatly improved in the past decades and their use in enhancing paraplegic mobility in the workplace has been recently pointed out. ${ }^{2}$ The use of this kind of orthosis would make the ergonomic requirements of paraplegic subjects more similar to that of normal users. In other words if the paraplegic subject is able to stand and to walk, the workplace needs not be modified for their sake.

In our country, the RGO (reciprocating gait orthosis) ${ }^{3}$ is the most widely used among modern orthoses, and a large number of subjects have been rehabilitated with it. In Rome alone (IRCCS S Lucia center), in the last 3 years 33 paraplegic patients have been rehabilitated with RGO. At present, 22 of them are still using the orthosis for about $2 \mathrm{~h}$ a day. Five subjects use it also in their workplace.

The aim of the present research was to assess the

Correspondence: F Felici energy demand necessary for work while wearing the RGO, in order to evaluate the suitability and the feasibility of this orthosis in a workplace. Energy demand must be equal or less than 4 mets $(\cong 14 \mathrm{ml}$ $\mathrm{O}_{2} \mathrm{~kg}^{-1} \mathrm{~min}^{-1}$ ), to be compatible with a normal working schedule. ${ }^{4}$ Heart rate, oxygen intake and pulmonary ventilation were measured in RGO rehabilitated paraplegic subjects and in normal subjects during the execution of some common working tasks. In paraplegic patients the measurements were taken whilst the subjects were sitting in their wheelchairs and when standing with RGO. In normal subjects measurements were taken only while standing. The maximal aerobic power (maximal oxygen intake) of paraplegic subjects was also measured by means of an ergometric test. In this way it was possible to assess the relative cost of the working activities with respect to their maximal energy possibilities.

\section{Material and methods}

Six paraplegic subjects (three males and three females) and six normal subjects (three males and three females) gave their informed consent and participated in the research. Their anthropometric data are reported in Table 1. $\dot{\mathrm{VO}} \mathrm{O}_{2}$ (oxygen intake), $\dot{\mathrm{V}} \mathrm{E}$ (expiratory ventilation rate), and HR (heart rate) were measured, with a sampling time of $30 \mathrm{~s}$, during the activities listed below 
Table 1 Anthropometric characteristics of subjects (mean values $\pm \mathrm{SD}$ )

\begin{tabular}{lccccc}
\hline & Sex & $n$ & $\begin{array}{c}\text { Age } \\
\text { (years) }\end{array}$ & $\begin{array}{c}\text { Stature } \\
(\mathrm{cm})\end{array}$ & \multicolumn{1}{c}{$\begin{array}{c}\text { Mass } \\
(\mathrm{kg})\end{array}$} \\
\hline \multirow{2}{*}{ RGO } & $\mathrm{F}$ & 3 & $36 \pm 13$ & $61 \pm 4$ & $53 \pm 11$ \\
& $\mathrm{M}$ & 3 & $22.3 \pm 3$ & $175 \pm 5$ & $64 \pm 4$ \\
Controls & $\mathrm{F}$ & 3 & $25 \pm 5$ & $160 \pm 2$ & $50 \pm 5$ \\
& $\mathrm{M}$ & 3 & $43 \pm 17$ & $174 \pm 6$ & $75 \pm 10$ \\
\hline
\end{tabular}

by means of a telemetering apparatus (K2 Cosmed). The reliability of this device has been shown. ${ }^{5}$ The device allowed the subject to perform the requested activity without any kind of discomfort.

\section{Reach space evaluation test}

The paraplegic subjects performed the tests standing wearing the RGO, and sitting in their wheelchairs. Pictures were taken during the working activities that will be mentioned later. The subjects were requested to move in the workplace as much as possible to reach every tool that would be necessary for the specific task that they were performing. A descriptive analysis of their moving ability and of their ability to reach the prefixed goal was performed. In all of the paraplegic subjects the reach space (RS) in standing and sitting postures was measured by pictures as shown in Figure 1 (A-D). Each subject sat in his/her own wheelchair. Following Nowak, ${ }^{1}$ we defined the individual absolute reach space by measuring the dimensions of forward and lateral arm reach in the two considered postures. Forward reach was measured from the centre of the shoulder. Lateral reach was measured from the centre of the sternum. In both cases measurements were drawn to the fingertip in the fully extended position of upper arm with the trunk fully extended. The actual reach space (ARS) was defined as the RS minus the hindrance $(\mathrm{H})$ due to wheelchair or RGO structure. Figures obtained were then normalised (total length equal to 100) to set in both conditions and in both postures the percentage reduction of reach space.

\section{Workplace tests}

The following work environments were considered: a mechanical workshop (room a), a photographic studio (room b) and a drawing studio (room c). In room a the following activities were performed: (1) turning a pulley in aluminium alloy on the lathe, (2) shaping the faces of an aluminium cube with a milling machine, (3) filing the surface of a metal block, (4) fastening bolts on an engine block. In room b the subject was requested to use (1) a projection printer, (2) a reproducing camera, and (3) a bromographic device. In room $c$ the subject performed a technical (pencil) drawing on a drawing table. In each of these activities the subject was requested to repeat the task without interruption. In the paraplegic subjects $\dot{\mathrm{VO}} \mathrm{O}_{2}, \dot{\mathrm{VE}}$, and HR measurements at rest were taken in standing and sitting
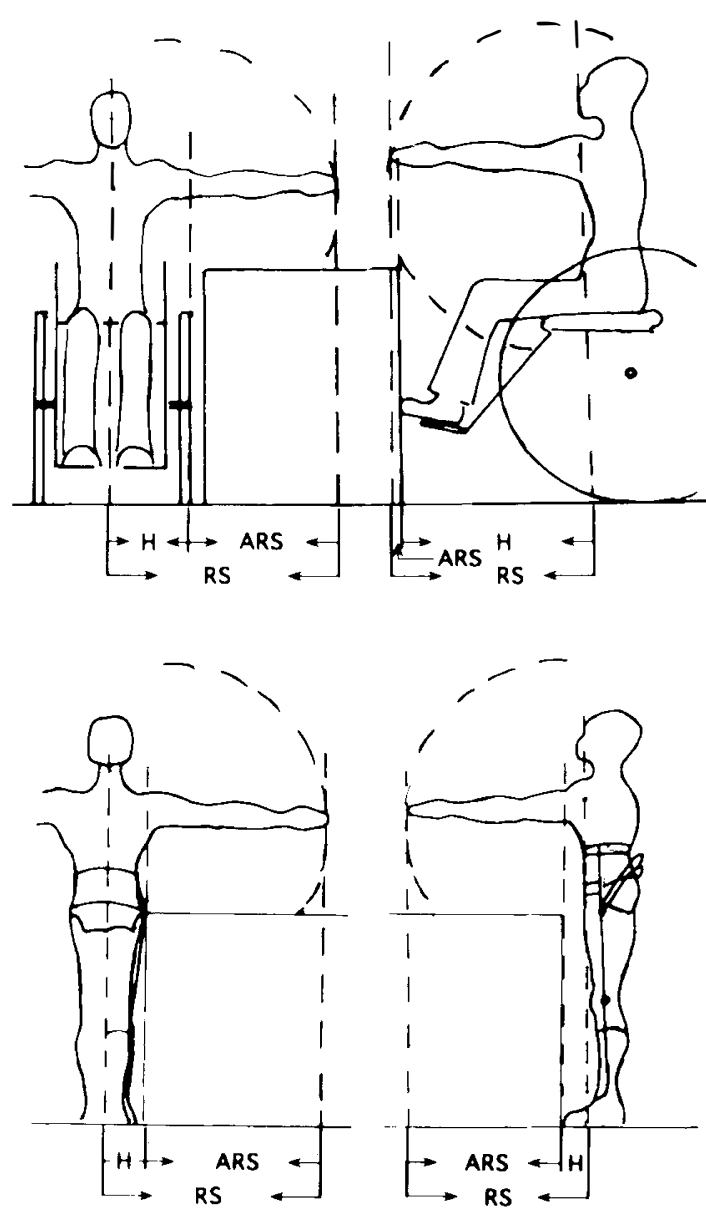

Figure 1 Reach space assessment. From left to right, from top to bottom: lateral reach and arm reach forward in the seated and in the standing erect postures. Diagram of the extent of the reduction of the reach space $(\mathrm{RC})$ : size of the actual reach space (ARS) and of the hindrance $(\mathrm{H})$ due to the wheelchair and to the RGO, respectively

postures. In the control group, rest values were measured only during standing. During the activity phase, $\dot{\mathrm{VO}_{2}}, \dot{\mathrm{VE}}$, and $\mathrm{HR}$ were measured until a stable value (steady state value) was reached. The steady state value was considered for the statistical analysis of comparisons. Measurements were taken only in subjects who had had previous experience with the tools described above and who used the RGO in their workplace. Six male subjects (three paraplegics and three normals) performed activities in the mechanical workshop; all the subjects participated in the rooms b and c tests. The paraplegic subjects performed each task both standing with the RGO and sitting in the wheelchair.

\section{Locomotion tests}

All paraplegic subjects participated in these tests. Each subject moved along an indoor walkpath at natural velocity, ie the velocity he/she felt as the most comfortable. The test was performed with both a wheelchair and a RGO. With both devices the 
measurements were taken, before starting the test, at rest, standing when the subject wore the RGO and sitting when the subject used the wheelchair to move. The measurements were continued throughout the test and during recovery. The locomotion test was prolonged for at least $10 \mathrm{~min}$ and only steady state values were considered in the following evaluation. In both cases the devices were personal and were used routinely by the subjects.

\section{Maximal ergometry test}

An arm cranking ergometry test specially designed for wheelchair athletes ${ }^{6}$ was utilised to assess the aerobic power of the paraplegic subjects of this research. Every 2 min the workload was incremented by 20 watts. The test was continued until the patient was exhausted. The subject performed the test sitting on his/her wheelchair. During the whole ergometric test a laboratory spirometric apparatus (Eos Spring, Jaeger) was used to measure $\dot{\mathrm{VO}}_{2}, \dot{\mathrm{V} C O} \mathrm{C}_{2}$ and $\dot{\mathrm{VE}}$. The ventilatory threshold was estimated by means of the equivalent method, ${ }^{7}$ to obtain an evaluation of the border line between prevalent aerobic methabolism and mixed aerobic and anaerobic methabolism. HR was measured on a ECG record.

The last two tests (locomotion and ergometry) were performed only by the paraplegic subjects. For each of these, the data obtained during each working activity and the measurements taken during locomotion with each device (RGO and wheelchair) were also compared both with the ventilatory threshold and with the peak values measured at the ergometry test.

\section{Statistical analysis}

A Student's $t$ test $^{8}$ was used to compare the physiological measurements $\left(\dot{\mathrm{VO}}_{2}, \dot{\mathrm{VE}}\right.$, and $\left.\mathrm{HR}\right)$ in the different activities and to compare for each working activity the values measured in the controls and in the patients. The $t$ test was utilised also to compare the results obtained when patients worked in the two conditions, sitting on a wheelchair or standing by means of the RGO. In all cases a $P$ value of 0.05 was used as level of significance.

\section{Results}

\section{Reach space}

When the subjects performed their working activity sitting in a wheelchair, their actual reach space (ARS) was very limited in comparison with the reach space available when standing with an RGO (Figure 1). A reduction of $93 \% \pm 6$ was found in the arm reach forward, when a subject was sitting in comparison with the $11 \% \pm 5$ reduction in the erect posture. The reduction of the lateral reach amounted to $22 \% \pm 2$ when the subject was standing and to $32 \% \pm 2$ when the subject was sitting. Based on these data the seated posture compared with standing erect caused a decrease of the ARS due to the hindrance $(\mathrm{H})$ of the wheelchair of $82 \%$ in the arm reach forward and of $10 \%$ in the lateral reach.

In the mechanical workshop, both at the lathe and at the milling machine, if the paraplegic subjects were sitting in a wheelchair, the workpiece had to be prepared by an able bodied assistant. When the same subjects were mobilised with an RGO, they were able to perform all the processing phases by themselves. Figure 2 shows a paraplegic subject in a photographic studio. Having the opportunity to stand allows the subject to reach and to handle conveniently all the tools that he/she needs even if the workplace is not specially designed for disabled people. The same situation was observed in the mechanical workshop, since all the instruments are clearly designed to be manipulated by a standing person. During the execution of the working tasks, no difference was observed in the reach space between paraplegics standing with the RGO and normal subjects.

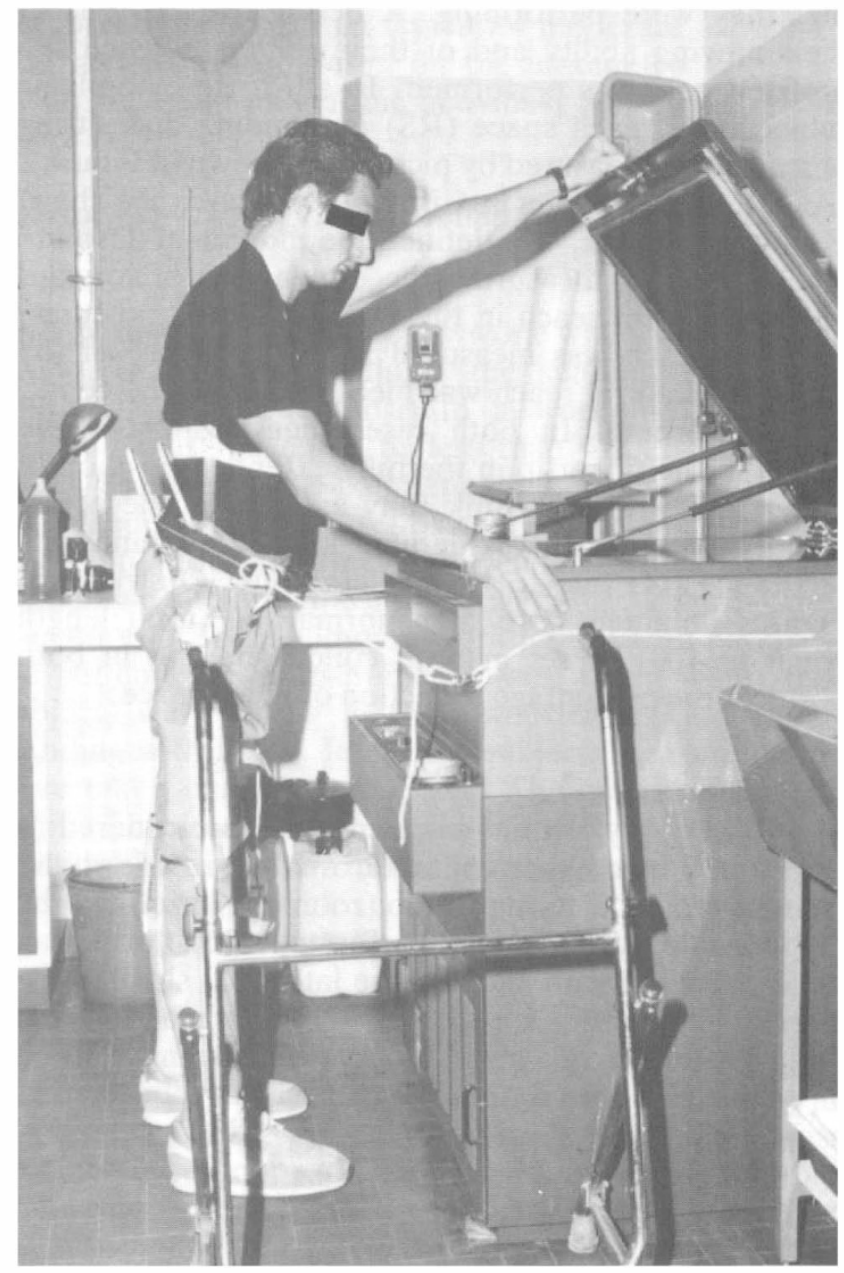

Figure 2 A paraplegic subject at work in the photographic studio. Evidence of increased mobility 
Workplace activities

The values of $\dot{\mathrm{V}} \mathrm{O}_{2}, \dot{\mathrm{V}} \mathrm{E}$ and $\mathrm{HR}$ measured in each subject during the activities performed in the workplace are presented in Table 2 as mean values \pm standard deviations. For each working activity paraplegic subjects were tested both when they sat in the wheelchair and when they stood by means of their RGO. In the table the activities whose range of physiological parameter values was the same are grouped together (eg milling and working at the lathe). For each activity the values measured in paraplegic subjects (both in the wheelchair and with the RGO) that were significantly different from those measured in the controls are marked in the table with an asterisk $(*)$. The activities where a significant difference was found between the values of the paraplegics standing with RGO and those of the paraplegics sitting in the wheelchair are marked with the symbol ${ }^{\circ}$. In both cases the symbol indicates the group in which the higher value was measured. The comparison between the $\dot{\mathrm{VO}}_{2}$ measured in control subjects and in paraplegic subjects performing the same activity was never found to be statistically different $(P>0.05)$. The comparison of the $\dot{\mathrm{VO}}_{2}$ between paraplegic subjects working in the two conditions (standing and sitting) was statistically higher only when they filed sitting in the wheelchair. The HR and $\dot{V E}$, on the other hand, were in many instances significantly different in the three groups of subjects $(P<0.05)$. The highest values of HR were found constantly in the RGO group.

Both in the paraplegic subjects and in the controls $\dot{\mathrm{V}} \mathrm{O}_{2}, \dot{\mathrm{V}} \mathrm{E}$ and $\mathrm{HR}$ measured during filing and fastening bolts were significantly higher than those measured when working at the lathe and milling machines or in the photo and drawing studios $(P<0.05)$. These latter jobs led to a very light metabolic energy demand as well as to very light cardiac and respiratory loads. However, all the investigated activities induced a more or less marked increment of the energy expenditure above the resting values.

In rest conditions (Table 2) the $\dot{\mathrm{V}} \mathrm{O}_{2}$ measured in paraplegic patients sitting in the wheelchair was significantly lower than that measured both in the same subject standing with RGO and in the controls (also in this condition the measure was taken in a standing position).

\section{Locomotion}

The metabolic cost of moving by means of a wheelchair was equivalent to that of walking with an RGO. However, the progression speed was very different, being in the former case almost 10 times higher than the latter. VE and HR are higher when the subjects used the RGO to move. In Table 3 , the mean values and standard deviations of $\dot{\mathrm{V}} \mathrm{O}_{2}, \dot{\mathrm{VE}}, \mathrm{HR}$ and speed measured during paraplegic subject locomotion with both devices are shown. In both kinds of locomotion, energy cost and HR were similar to the most expensive tasks, ie filing and fastening bolts.

\section{Ergometry}

The HR at maximal power request was very close to the maximum predictable in accordance with the subject's age. At the ventilatory threshold, the $\mathrm{V}_{2}$ was about $77 \%$ of the peak value. In comparison, the $\dot{\mathrm{VO}}_{2}$ cost of all the work activities, including the most expensive, like ambulating or filing, was significantly less, corresponding to about $60 \%$ of the $\dot{\mathrm{VO}}_{2}$ peak.

Table $2 \dot{\mathrm{V}} \mathrm{O}_{2}, \dot{\mathrm{V} E}$ and $\mathrm{HR}$ of RGO and control subjects at rest and at work (mean values \pm SD). For paraplegic patients, wheelchair and RGO data are reported.

\begin{tabular}{|c|c|c|c|c|}
\hline Subjects' condition & & $\begin{array}{c}\dot{V} \mathrm{O}_{2} \\
\left(\mathrm{ml} \mathrm{kg}^{-1} \min ^{-1}\right)\end{array}$ & $\begin{array}{c}\dot{V} E \\
\left(\mathrm{ml} \mathrm{kg}^{-1} \min ^{-1}\right)\end{array}$ & $\begin{array}{c}H R \\
\text { (beats } \text { min }^{-1} \text { ) }\end{array}$ \\
\hline Milling or lathe & $\begin{array}{l}\text { Wheelchair } \\
\text { RGO } \\
\text { Controls }\end{array}$ & $\begin{array}{l}6.5 \pm 0.5 \\
6.8 \pm 0.9 \\
5.5 \pm 0.9\end{array}$ & $\begin{array}{l}253 \pm 29^{*} \\
302 \pm 54^{*} \\
187 \pm 45\end{array}$ & $\begin{array}{c}112 \pm 7^{*} \\
114 \pm 17^{*} \\
86 \pm 7\end{array}$ \\
\hline Fastening bolts & $\begin{array}{l}\text { Wheelchair } \\
\text { RGO } \\
\text { Controls }\end{array}$ & $\begin{array}{l}9.2 \pm 1 \\
8.4 \pm 0.8 \\
9 \pm 1.2\end{array}$ & $\begin{array}{l}413 \pm 28^{*} \\
440 \pm 42^{*} \\
255 \pm 32\end{array}$ & $\begin{array}{r}128 \pm 7^{*} \\
130 \pm 5^{*} \\
97 \pm 12\end{array}$ \\
\hline Filing & $\begin{array}{l}\text { Wheelchair } \\
\text { RGO } \\
\text { Controls }\end{array}$ & $\begin{array}{l}13.8 \pm 1.2^{\circ} \\
11.2 \pm 1.3 \\
12.6 \pm 1.9\end{array}$ & $\begin{array}{l}439 \pm 38 \\
472 \pm 44 \\
431 \pm 70\end{array}$ & $\begin{array}{l}130 \pm 7 \\
150 \pm 5^{\circ} \\
120 \pm 26\end{array}$ \\
\hline Drawing or photo & $\begin{array}{l}\text { Wheelchair } \\
\text { RGO } \\
\text { Controls }\end{array}$ & $\begin{array}{l}5.3 \pm 0.6 \\
5.6 \pm 0.6 \\
5.4 \pm 1.2\end{array}$ & $\begin{array}{l}177 \pm 29 \\
212 \pm 26^{\circ} \\
196 \pm 43\end{array}$ & $\begin{aligned} 98 & \pm 6 \\
114 & \pm 6^{* \circ} \\
86 & \pm 9\end{aligned}$ \\
\hline Rest & $\begin{array}{l}\text { Wheelchair } \\
\text { RGO } \\
\text { Controls }\end{array}$ & $\begin{array}{l}4.0 \pm 1 \\
5.3 \pm 1^{\circ} \\
4.9 \pm 0.6^{*}\end{array}$ & $\begin{array}{l}170 \pm 20 \\
198 \pm 41 \\
173 \pm 25\end{array}$ & $\begin{aligned} 85 & \pm 5 \\
100 & \pm 5^{* \circ} \\
78 & \pm 2\end{aligned}$ \\
\hline
\end{tabular}

*denotes a statistically significant difference from controls $(P<0.05)$. The symbol ${ }^{\circ}$ is used to mark a statistical difference between paraplegic subjects in the two conditions, standing with the RGO and sitting on the wheelchair. The symbols indicate the group where the value is higher 
Table 3 Comparison between cost of locomotion using the RGO and using the wheelchair (mean values \pm SD). Results of ergometric test are also reported.

\section{Locomotion}

Device used

Wheelchair RGO

Maximal ergometry test

$$
\begin{array}{cc}
\dot{\mathrm{V}} \mathrm{O}_{2} & \dot{\mathrm{V}} \\
\left(\mathrm{ml} \mathrm{kg}^{-1} \mathrm{~min}^{-1}\right) & \left(\mathrm{ml} \mathrm{kg}^{-1} \mathrm{~min}^{-1}\right) \\
10 \pm 0.3 & 457 \pm 6.8 \\
10.8 \pm 0.8 & 374 \pm 17.5
\end{array}
$$

$$
\underset{\left(\mathrm{ml} \mathrm{kg}^{-1} \mathrm{~min}^{-1}\right)}{\dot{\mathrm{V}}}
$$$$
18.2 \pm 1.2
$$

$$
\begin{gathered}
\text { HR } \\
\text { (beats } \text { min }^{-1} \text { ) } \\
117 \pm 3 \\
140 \pm 4
\end{gathered}
$$
$\dot{\mathrm{V}} \mathrm{O}_{2 \text { trh }}$ $\left(\mathrm{ml} \mathrm{kg}^{-1} \mathrm{~min}^{-1}\right)$
$14 \pm 2.5$

\author{
$\dot{\mathrm{VE}}$ \\ $\left(\mathrm{ml} \mathrm{kg} \mathrm{min}^{-1}\right)$ \\ $650 \pm 47$
}

$$
\begin{gathered}
\begin{array}{c}
\text { Speed } \\
\left(\mathrm{m} \mathrm{s}^{-1}\right)
\end{array} \\
1.23 \pm 0.04 \\
0.18 \pm 0.03
\end{gathered}
$$

$\mathrm{HR}$
(beats $\left.\min ^{-1}\right)$
$165 \pm 2$

\section{Discussion}

\section{Reach space and standing posture}

The results of the present study show that the RGO offers both advantages and disadvantages. First, there is a marked improvement in reach space compared to the traditional wheelchair. Our results demonstrate that the hindrance due to wheelchair dimensions greatly reduces the possibility of working with tools which do not allow the subject to push the wheelchair under the working table. In the mechanical workshop, as well as in the photographic and drawing studios, all instruments presented this disadvantage. Standing with the RGO overcame this problem completely. Actually, the advantages offered by the RGO are more impressive than those showed by our measurements on effective reach space. In fact, only the erect posture allows the subject to control properly many of the process phases which we have considered, such as focusing the image on photographic tools. Figure 2 shows clearly how in a workshop an orthosis such as the RGO greatly improves the paraplegic's reach space. Secondly, no special changes in the working environment must be adopted to allow disabled people to use tools or any kind of device. Furthermore, the mobility of the subjects wearing a RGO is markedly enhanced compared to the mobility of the same subject sitting in a wheelchair. Wheelchairs, in fact, are too cumbersome to move among the workplace's furniture. Although the deambulator is cumbersome too, its hindrance is much less than that of wheelchair.

The metabolic energy demand and cardiac load are the same wearing the RGO as those required when the same subject performs the same activity sitting in a wheelchair. In other words, there is no special reason from a metabolic point of view to use the wheelchair during a working performance.

Some disadvantages need to be pointed out. The individually designed RGO orthosis is perfectly balanced, thus allowing the paraplegic subject to stand with minimal metabolic energy involvement. As happens in normals, when a paraplegic person stands with the $\mathrm{RGO}, \mathrm{VO}_{2}$ and $\mathrm{HR}$ at rest are higher than when the same subject sits in the wheelchair. The HR, however, was significantly higher than in controls and then its increment was higher than that of the $\dot{\mathrm{V}} \mathrm{O}_{2}$. This discrepancy between the $\mathrm{HR}$ and the $\mathrm{V}_{2}$ can be interpreted attributing the high $\mathrm{HR}$ to the isometric contraction activity of the trunk and upper limb musculature. A paraplegic subject who wears the RGO can control his/her balance by means of a delicate regulation of the active muscles which implies repeated isometric contractions. Furthermore, when the RGO subject walks, he/she must grasp the deambulator firmly and this action requires an isometric contraction of finger flexors, elbow and shoulder extensors. ${ }^{9}$ During isometric contractions the muscles may press on the blood vessels determining a relative occlusion. ${ }^{10}$ To obtain a better definition of the workload imposed on the heart it would be necessary to measure the arterial blood pressure. Unfortunately, in most cases under study, particularly those that promoted the greater increases of HR, reliable data could not be obtained with a non-invasive technique.

The cost of moving with a wheelchair was consistent with data reported by other authors. ${ }^{11,12}$ Data related to RGO walking are similar to those previously reported in the literature. ${ }^{13-15}$ Both kinds of locomotion have the same $\dot{\mathrm{V}} \mathrm{O}_{2}$ and these values are comparable with those of normal subjects walking at spontaneously chosen (natural) speed. ${ }^{16}$ However, able bodied people's speed is at least five times higher than paraplegic walking speed, and the speed that the paraplegic subject spontaneously chooses as natural when using the wheelchair is 10 times higher than when using the RGO. Furthermore, the range of speed that can be covered using the RGO is very limited, the natural speed being not only very low but also very close to the highest speed performable. However, this latter drawback is amply compensated for by the fact that, in many instances, a high speed of locomotion in a working environment is usually not requested and it would not justify the use of the wheelchair.

\section{Energetics of working activities}

Based on ergometry test results it was possible to establish that all the activities considered in this study were performed utilising a prevalent aerobic metabolism. In fact in all the working tasks and during locomotion the $\dot{\mathrm{V}} \mathrm{O}_{2}$ values were lower than those measured at the ventilatory threshold.

The maximum working time largely depends upon metabolic requests. Light work has been defined by 
Monod and Pottier ${ }^{4}$ as an activity which implies a $\dot{\mathrm{V}} \mathrm{O}_{2}$ of about $10.7 \mathrm{ml} \mathrm{kg}^{-1} \mathrm{~min}^{-1}$, a $\dot{\mathrm{VE}}$ of 285.7 $\mathrm{ml} \mathrm{kg}^{-1} \mathrm{~min}^{-1}$ and a HR of 100 beats $\mathrm{min}^{-1}$; an activity with these characteristics can be maintained for $8 \mathrm{~h}$. In the activities studied in the present research, the $\dot{\mathrm{V}} \mathrm{O}_{2}$, $\dot{V} E$ and HR slightly exceeded these values only during filing and fastening bolts. In all the other working activities, both those performed in the mechanical workplace and those performed in the drawing and photo studios and also during locomotion, the metabolic energy demand was compatible with light work, both sitting in a wheelchair and standing with an RGO. Assuming that an equal amount of time was spent in the various activities, including locomotion, that is including the time spent moving from place to place in the working environment, from the figures reported in Tables 2 and 3 , the results showed an average $\dot{\mathrm{VO}}_{2}$ of less than $9 \mathrm{ml} \mathrm{kg}^{-1} \mathrm{~min}^{-1}$ in both conditions, ie standing and sitting. This $\dot{\mathrm{VO}}_{2}$ value is well within the above indicated limit for light work and the considered tasks could be performed compatibly with the normal duration of a working day ( $8 \mathrm{~h}$ a day, 5 days a week). Filing seems to be the heaviest work among those we considered, both for paraplegic persons and controls. In this particular case, $\mathrm{VO}_{2}$, is at the boundaries between moderate and heavy work (moderate: $\dot{\mathrm{V}} \mathrm{O}_{2}=21.4 \mathrm{ml} \mathrm{kg}^{-1} \mathrm{~min}^{-1}$; heavy: $\dot{\mathrm{V}}_{2}=28.6 \mathrm{ml} \mathrm{kg}^{-1}$ $\min ^{-1}$ ). Thus, in this case, the maximal duration of working activity should be reduced from 8 to $5 \mathrm{~h}$ a day.

Different indications seem to arise from the VE and HR data obtained during RGO working. Comparing the results of this study with the $\dot{V} E$ and $H R$ values provided by Monod and Pottier ${ }^{4}$ (moderate: $\dot{\mathrm{V} E}=500$ $\mathrm{ml} \mathrm{kg}{ }^{-1} \min ^{-1}, \quad \mathrm{HR}=120$ beats $\mathrm{min}^{-1}$; heavy: $\dot{\mathrm{VE}}=$

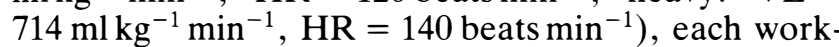
ing task, and locomotion as well, should be included in the moderate activities. The maximum allowable duration of a working activity of moderate intensity is considered to be between 5 and $8 \mathrm{~h}$. In other words, classifying an activity as light, moderate or heavy has important practical implications. This categorisation can be easily performed by measuring the HR, since it seems the most sensitive to the kind of work performed.

On the basis of the present study, two final considerations can be drawn: first, the rehabilitation of paraplegic subjects with an RGO provided an effective way for a person to recover productive activities. Secondly, it seems necessary to submit each individual to a physical examination during controlled exercise to judge the maximal tolerable work load that can be asked of each subject.

\section{References}

1 Nowak E. Workplace for disabled people. Ergonomics 1989; 32: $1077-1088$.

2 Kantor C et al. Report on a conference on motor prostheses for workplace mobility of paraplegic patients in North America. Paraplegia 1993; 31: 439-456.

3 Douglas R, Larson PF, D'Ambrosia RD, McCale RF. The LSU reciprocation gait orthosis. Orthopaedics 1983; 6: 834-39.

4 Monod H, Pottier M. Les adaptions respiratoires et circulatoires du travail muscolaire. In: J. Sherrer (ed). Physiologie du Travail. Masson et CIE, Tome 1, 209-291.

5 Lucia A, Fleck SJ, Gotshall RW, Kearney JT. Validity and reliability of the Cosmed K2 instrument. Int J Sports Med 1993; 14: $380-386$.

6 Marchetti et al. Idoneita' allo Sport Agonistico per Atleti su Sedia a Ruote. Editor Centro Ricerche Clinica S. Lucia, Roma, I Quaderni, 1992, pp 64-72.

7 Wassermann K, Whipp B, Koyal S, Beaver W. Anaerobic threshold and respiratory gas exchange during exercise. J Appl Physiol 1973; 35: 236-243.

8 Sachs L. Applied Statistics. A Handbook of Techniques, 2nd edn. Springer-Verlag: New York, Berlin, Heidelberg, Tokyo, 1984, pp 264-275.

9 Marchetti $\mathrm{M}$ et al. A first approach to RGO paraplegic walking. Ninth Congress of the International Society of Electrophysiology and Kinesiology, Florence, Italy, 28 June - 2 July 1992 , Book of Abstracts, 119

10 Lind AR. Cardiovascular adjustment to isometric contractions: static effort. In: Shepherd JT, Abboud FM, Geiger SR (eds). Handbook of Physiology. The Cardiovascular System III, 3(2). American Physiological Society: Bethesda, Maryland, 1983, pp 947-966.

11 Hildebrandt $G$ et al. Energy cost of propelling wheelchair at various speeds: cardiac response and effect on steering accuracy. Arch Phys Med Rehabil 1970; 51: 131-136.

12 Stoboy H, Wilson RB. Muscle strength and electrical activity, heart rate and energy cost during isometric contractions in disabled and non disabled. Paraplegia 1971; 8: 217

13 Hirokawa $\mathrm{S}$ et al. Energy consumption in paraplegic ambulation using the reciprocating gait orthosis and electric stimulation of the thigh muscles. Arch Phys Med Rehabil 1990; 71: 687-694.

14 Nene AV, Patrick JH. Energy cost of paraplegic locomotion with the ORLAU parawalker. Paraplegia 1989; 27: 5-18.

15 Puricelli $\mathrm{R}$ et al. Il consumo energetico durante il cammino di pazienti paraplegici traumatici adulti. Eur Med Phys 1993; 29: 235-44.

16 Di Prampero PE. The energy cost of human locomotion on land and in water. Int J Sports Med 1986; 7: 55-72. 